\title{
Audiological outcomes of cochlear implantation in Waardenburg Syndrome
}

\author{
Ana Tereza de Matos Magalhães', Paola Angélica Samuel', Maria Valeria Schimdt Goffi-Gomez², Robinson Koji Tsuji', \\ Rubens Brito ${ }^{3}$, Ricardo Ferreira Bento ${ }^{3}$.
}

1) Audiologist. Department of Otolaryngology, University of São Paulo School of Medicine, São Paulo, Brazil.

2) Audiologist, PhD. Department of Otolaryngology, University of São Paulo School of Medicine, São Paulo, Brazil.

3) MD, PHD. Department of Otolaryngology, University of São Paulo School of Medicine, São Paulo, Brazil.

Institution: Department of Otolaryngology, University of São Paulo School of Medicine São Paulo/SP - Brazil

Mailing address: Ana Tereza de Matos Magalhães - Rua Capote Valente, 432 conjunto 14 - São Paulo / SP - Brazil - Zip code: $05409-001$ - E-mail: anatereza@forl.org.br Article received on February 11 $11^{\text {th }}, 2013$. Article accepted on April $23^{\text {th }}, 2013$.

\section{SUMMARY}

Introduction: The most relevant clinical symptom in Waardenburg syndrome is profound bilateral sensorioneural hearing loss. Aim: To characterize and describe hearing outcomes after cochlear implantation in patients with Waardenburg syndrome to improve preoperative expectations.

Method: This was an observational and retrospective study of a series of cases. Children who were diagnosed with Waardenburg syndrome and who received a multichannel cochlear implant between March 1999 and July 2012 were included in the study. Intraoperative neural response telemetry, hearing evaluation, speech perception, and speech production data before and after surgery were assessed.

Results: During this period, 806 patients received a cochlear implant and 10 of these (1.2\%) were diagnosed with Waardenburg syndrome. Eight of the children received a Nucleus $24^{\circledR}$ implant and 1 child and 1 adult received a DigiSonic SP implant. The mean age at implantation was 44 months among the children. The average duration of use of a cochlear implant at the time of the study was 43 months. Intraoperative neural responses were present in all cases. Patients who could use the speech processor effectively had a pure tone average of $31 \mathrm{~dB}$ in free-field conditions. In addition, the MUSS and MAIS questionnaires revealed improvements in speech perception and production. Four patients did not have a good outcome, which might have been associated with ineffective use of the speech processor.

Conclusion: Despite the heterogeneity of the group, patients with Waardenburg syndrome who received cochlear implants were found to have hearing thresholds that allowed access to speech sounds. However, patients who received early intervention and rehabilitation showed better evolution of auditory perception.

Keywords: Hearing; Cochlear Implants; Hearing Loss; Waardenburg Syndrome; Speech Perception.

\section{INTRODUCTION}

Cochlear implantation outcomes are dependent on several factors that lead to a good prognosis, such as early diagnosis and intervention, systematic rehabilitation, family permeability, and type of communication, as well as other factors related to hearing loss including etiology, period of deafness, and the presence of other associated impairments (1-3).

Genetic causes of deafness include Waardenburg syndrome (WS), which accounts for $2 \%-5 \%$ of patients with congenital hearing loss (4). WS is an autosomal dominant disease characterized by hyperplasia of the medial portion of the eyebrows, a broad nasal root, heterochromia iris, white forelock or early graying, and congenital sensorineural hearing loss (5).

The most relevant clinical symptom in WS is the hearing loss, which can be unilateral or bilateral, and moderate to profound. Severe to profound deafness is more evident in patients with Type I and Type II WS, with an incidence of $35 \%-75 \%$ and $55 \%-91 \%$, respectively (6). Cochlear implantation is indicated for patients with bilateral and severe to profound hearing loss who are unable to benefit from conventional hearing aids.

Few studies have evaluated the audiological outcomes of cochlear implantation in users with syndromes. Some have noted limited success depending on the characteristics associated with the syndrome and the age at implantation. Studies of WS have reported good outcomes for those with no other impairments associated with the syndrome (7-10).

The purpose of this study was to characterize and describe hearing outcomes after cochlear implantation in patients with WS to improve preoperative expectations. 


\section{MethOD}

This was a retrospective and observational study of a series of cases and was performed from March 1999 through July 2012. Data wee collected from the cochlear implant team database. Patients who met the following criteria were included in the study:

- Diagnosed with WS;

- Multichannel cochlear implant user.

The following data were collected:

- Age at diagnosis of deafness;

- Age at rehabilitation initiation;

- Age at cochlear implant activation;

- Duration of cochlear implant use (in months);

- Number of active electrodes;

- Intraoperative neural telemetry results;

- Aided average pure tone threshold in sound field c before and after surgery;

- Pre- and post-operative speech perception and production test results.

Intraoperative neural telemetry data were recorded by Nucleus NRT $3.1^{\circledR}$ or Custom Sound EP $2.0^{\circledR}$ software from Cochlear Corporation ${ }^{\circledR}$. A response was considered present when at least 3 electrodes presented reproducible responses. Electrical Auditory Brainstem Response (EABR) data were recorded by Bio-logic v.7.0 $0^{\circledR}$ and stimulated by Digistim $^{\circledR}$ from Neurelec ${ }^{\circledR}$.

Free field audiometry data were collected using Madsen Midimate $622^{\circledR}$ and retrieved from patient records. Where no threshold was available (such as during preoperative assessment), a value of $130 \mathrm{~dB}$ was used to calculate the average (greater than the amplifier limit); the calculation was performed according to the BIAP recommendation (11).

Speech perception and production were evaluated using our standard protocols and were assessed according to age (12). For children up to the age of 4 years 11 months, the Early Perception Test (ESP) was used (the Portuguese form by Orlandi and Bevilacqua (13)). For children aged 5 years or older, the Portuguese form of the Glendonald Auditory Screening Procedure (GASP) was used (14). In both tests, the results were classified into the speech perception categories described by Geers (15).

Two inventories were submitted to the parents, one addressing information on the frequency with which the child showed significant auditory behaviors in their everyday life (IT-MAIS - Infant-Toddler Meaningful Auditory Integration Scale) $(16,17)$, the other providing information on the frequency with which the child demonstrated
Table I. Degree of permeability of the family and the cognitive style of the children.

\begin{tabular}{lc}
\hline Score & Classification \\
\hline $90-100 \%$ & Excellent \\
$60-89 \%$ & Satisfactory \\
$<59 \%$ & Low \\
\hline
\end{tabular}

behaviors associated with oral language (MUSS-Meaningful Use of Speech Scale) $(18,19)$. Both questionnaires were applied before and after cochlear implantation.

The degree of permeability of the family to the therapeutic process was evaluated following the Latin American Protocol (20), and was classified as shown in Table 1. The cognitive style of the children was assessed through observation by the clinician and/or by parent report of behaviors associated with child development.

The performance of adults was also evaluated using standard protocols (12). The speech perception tests were performed with sentences in open and closed sets.

\section{RESULTS}

During this period, 806 patients received a cochlear implant. Of these, 10 (1.2\%) were diagnosed with WS. The demographic data of this sample are shown in Tables 2 and 3 .

Preoperative evaluations performed before cochlear implantation showed that despite the use of conventional hearing aids, none of the patients could perceive speech (category zero)(15). Eight of the children received a Nucleus $24^{\circledR}\left(\right.$ Cochlear Corporation $\left.^{\circledR}\right)$ implant and 1 child and 1 adult received a DigiSonic SP (Neurelec $\left.{ }^{\circledR}\right)$ implant. Case 10 is an adult with pre-lingual hearing loss, oral language communication and good lip reading.

Intraoperative neural responses were present in all of the cases. Among the children, the mean age at the time of implantation was 44 months. The average duration of use of a cochlear implant was 43 months at the time of the study. Patients who could effectively use the speech processor had a pure tone average of $31 \mathrm{~dB}$ in free field conditions, and the MUSS and MAIS questionnaires showed clinical improvements in speech perception and production (Table 4).

On the other hand, 4 patients who were unable to use the speech processor effectively had a pure tone average of $67.5 \mathrm{~dB}$ in free field conditions. In addition, their 
Table 2. Characteristics of cochlear implant patients.

\begin{tabular}{|c|c|c|c|c|c|c|}
\hline ID & SEX* & $\begin{array}{l}\text { Implantationage } \\
\text { (months) }\end{array}$ & Implantedear & $\begin{array}{c}\text { Number of electrodes } \\
\text { activated }\end{array}$ & $\begin{array}{c}\text { Intraoperative neural } \\
\text { telemetry }\end{array}$ & $\begin{array}{c}\text { Brand of cochlear } \\
\text { implant } * * * 6\end{array}$ \\
\hline I.MLFN & $F$ & 53 & Right & $22 / 22$ & Present & N24 \\
\hline 2.JLCS & $M$ & 20 & Right & $22 / 22$ & Present & N24RE \\
\hline 3. GAS & M & 36 & Right & $22 / 22$ & Present & N24 \\
\hline 4.MSLG & M & 18 & Right & $22 / 22$ & Present & N24 \\
\hline 5.ASLG & $\mathrm{F}$ & 106 & Left & $22 / 22$ & Present & N24 \\
\hline 6. AMNCT & F & 71 & Right & $22 / 22$ & Present & N24RE \\
\hline 7.ACAFD & $F$ & 38 & Right & $22 / 22$ & Present & N24RE \\
\hline 8.VMM & M & 32 & Right & $22 / 22$ & Present & N24RE \\
\hline 9. ERM & M & 30 & Left & $18 / 20$ & Present & Digisonic \\
\hline 10.AAC & $\mathrm{F}$ & 22 years & Right & $19 / 20$ & Present & Digisonic \\
\hline
\end{tabular}

${ }^{*} \mathrm{M}=$ male; $\mathrm{F}=$ female; ${ }^{*} \mathrm{~N} 24=$ Nucleus $24 ; \mathrm{N} 24 \mathrm{RE}=$ Nucleus 24 Freedom

Table 3. Data on hearing loss, rehabilitation, degree of permeability of the family, and the cognitive style of the children.

\begin{tabular}{|c|c|c|c|c|c|c|c|c|}
\hline ID & $\begin{array}{c}\text { Diag. } \\
\text { (months) }\end{array}$ & $\begin{array}{c}\text { Hearingaid } \\
\text { (months) }\end{array}$ & $\begin{array}{l}\text { Rehab. } \\
\text { (months) }\end{array}$ & Rehabilitation & $\begin{array}{c}\text { Number of sess. } \\
\text { (perweek) }\end{array}$ & Freq. & Permeabil & $\begin{array}{l}\text { Cognitive } \\
\text { Style }\end{array}$ \\
\hline I.MLFN & 6 & 15 & 12 & Total Communicat. & Once & Inconsistent & Low & Satisfactory \\
\hline 2.JLCS & 10 & 16 & 12 & Audio-oral & Twice & Consistent & Excellent & Satisfactory \\
\hline 3. GAS & 14 & 16 & 16 & Audio-oral & Twice & Consistent & Excellent & Satisfactory \\
\hline 4.MSLG & 9 & 12 & 15 & Audio-oral & Twice & Inconsistent & Low & Low \\
\hline 5.ASLG & 12 & 36 & 36 & Audio-oral & Twice & Inconsistent & Low & Satisfactory \\
\hline 6.AMNCT & 20 & 24 & 24 & Audio-oral & Twice & Consistent & Low & Satisfactory \\
\hline 7.ACAFD & 20 & 26 & 26 & Audio-oral & Twice & Consistent & Excellent & Low \\
\hline 8.VMM & 5 & 18 & 12 & Audio-oral & Twice & Consistent & Satisfactory & Satisfactory \\
\hline 9. ERM & 6 & 14 & 14 & Audio-oral & Twice & Consistent & Satisfactory & Low \\
\hline I0.AAC & 7 & 24 & 24 & Audio-oral & Twice & Consistent & - & - \\
\hline
\end{tabular}

ID: identification; Diag: Age at diagnosis; Hearing aid: Age when began using hearing aids; Rehab.: Beginning of rehabilitation; sess.: sessions; Freq.: Frequency of rehabilitation; Permeabil: Degree of permeability of the family.

Table 4. Audiological outcomes and speech perception among children with a cochlear implant.

\begin{tabular}{|c|c|c|c|c|c|c|c|c|c|c|}
\hline \multirow[t]{2}{*}{ ID } & \multirow[t]{2}{*}{ Effective use of $\mathrm{Cl}$} & \multirow[t]{2}{*}{ Time of $\mathrm{Cl}$ use } & \multicolumn{2}{|c|}{ PTA (em dBNA) } & \multicolumn{2}{|c|}{ Category } & \multicolumn{2}{|c|}{ IT-MAIS/MAIS } & \multicolumn{2}{|c|}{ MUSS } \\
\hline & & & Pre Cl & Pos Cl & Pre Cl & Pos Cl & Pre Cl & Pos Cl & Pre Cl & Pos Cl \\
\hline I. MLFN & Yes & 174 & 110 & 25 & 0 & 5 & $25 \%$ & $100 \%$ & $20 \%$ & $100 \%$ \\
\hline 2. JLCS & Yes & 60 & 105 & 20 & 0 & 6 & $0 \%$ & $100 \%$ & $40 \%$ & $97.5 \%$ \\
\hline 3. GAS & Yes & 54 & 105 & 25 & 0 & 6 & $7.5 \%$ & $100 \%$ & $45 \%$ & $100 \%$ \\
\hline 4.MSLG & No & 48 & 100 & 60 & 0 & | & $30 \%$ & $17.5 \%$ & $25 \%$ & $2.5 \%$ \\
\hline 5.ASLG & No & 36 & 70 & 50 & 0 & 2 & $55 \%$ & $70 \%$ & $80 \%$ & $85 \%$ \\
\hline 6. AMNCT & No & 24 & 75 & 50 & 0 & | & $0 \%$ & $60 \%$ & $0 \%$ & $75 \%$ \\
\hline 7.ACAFD & No & 6 & $\mathrm{ABS}$ & 110 & 0 & 0 & $10 \%$ & $30 \%$ & $40 \%$ & $37 \%$ \\
\hline 8.VMM & YES & 24 & 75 & 30 & 0 & 4 & $5 \%$ & $75 \%$ & $20 \%$ & $80 \%$ \\
\hline 9. ERM & YES & 6 & $A B S$ & $N R$ & 0 & I & $0 \%$ & $20 \%$ & $0 \%$ & $15 \%$ \\
\hline
\end{tabular}

CI: cochlear implant; PTA (Pure tone average) Average threshold at $500 \mathrm{~Hz}$ and $4000 \mathrm{~Hz}$ (11); ABS = Absent; NR=unrealized; Category: Category of speech perception (15).

MUSS and MAIS questionnaire responses did not show any improvement in speech perception or production.

Case 10 was able to discriminate all of the vowels and $80 \%$ of a closed-set sentence after 9 months of using the speech processor.

\section{DISCUSSION}

All patients were diagnosed with severe to profound congenital hearing loss, which is in accordance with Barzotto and Folador (21), who showed that the most common form 
of hearing loss in WS is profound sensorineural. The prevalence of patients with WS who received a cochlear implant in this study was $1.2 \%$, which is close to the value generally reported in the literature $(8-10,22)$.

During the pre-implant evaluation, no patient was found to have benefited from conventional hearing aids, which corresponds to category 0 of speech perception and an inability to detect speech sounds. Thus, cochlear implantation was indicated.

All patients had complete insertion of electrodes and showed an intraoperative neural response, which means that the auditory nerve responded to the first electrical stimulation of the cochlear implant. Guedes et al.(1) showed that adult patients who showed intraoperative telemetry responses had better results in speech perception tests, but this relationship was not statistically significant among children.

Assessment of the hearing outcomes of all patients who were able to use the cochlear implant effectively showed that all had audiometric thresholds that enabled perception of speech sounds (according to the audiogram of Portuguese speech sounds) (23).

The IT-MAIS questionnaire results also showed significant clinical improvements in most cases, reflecting improvements in listening skills, not only for detection, but also for the recognition of some sounds, since most of the patients had a good hearing threshold. Kubo et al. (3) showed that after 6 to 12 months of use of a cochlear implant, children were able to distinguish and recognize sounds. In cases 4, 5, and 7 in the present study no clinical improvement was detected by IT-MAIS because the child didn't use the cochlear implant effectively, that is, there were care and maintenance problems as well as infrequent use of the implant during the rehabilitation process.

The MUSS results, which reflect oral language skills, showed slow improvements. These skills are dependent on daily experience, systematic rehabilitation, and stimulation by the family according to Kobo et al. (3). In our study, we found that children with low family permeability did not show any difference in their MUSS responses after cochlear implantation. Cases 4 and 5 are brothers and the family was not involved with their therapy or the fitting of their speech processors. In case 7, the family stopped using the speech processor because the child did not seem to improve.

These findings indicate that cochlear implants provide access to speech sounds, but that the development of auditory and language skills is dependent on systematic rehabilitation and family involvement (2).
There are a few studies of cochlear implantation in patients with syndromes in the literature, and these show that patients who have no other associated intellectual impairments, who receive their implant early, and who are subject to sufficient stimulation have good outcomes (710, 24).

In cases 2 and 3 in the present study, significant improvements in speech perception were observed and the family was also a meaningful participant in the therapeutic process. In case 1 , however, although an improvement in hearing behavior was observed, the patient's oral language was below average after implantation. The family showed a low level of participation in the patient's rehabilitation process and there was inconsistent use of the implant owing to poor care of the equipment, which led to numerous maintenance and technical assistance events, and thus undermined the patient's performance.

Out of the 10 cases described here, 3 (cases 5, 6, and 7) presented with late fitting of hearing aids, late auditory rehabilitation, and late implantation, which was reflected in their speech perception tests. Several studies have shown that children experience greater benefits from cochlear implantation when the implant is fitted when they are younger than age 2 , which is the ideal period for better leveraging the outcomes of the cochlear implant $(25,26)$. These children may show development patterns similar to those of children with normal hearing (27).

Andrade et al. (10) also confirmed that prelingually deafened WS children who have prior nonsignificant or marginal benefit from acoustic amplification but normal inner ear anatomy are potentially good candidates for audio-oral rehabilitation with a cochlear implant. Postoperative performance outcomes of $7 \mathrm{ca}-$ ses with WS were also assessed and compared to results obtained by children with non-syndromic congenital deafness. No statistical differences were found between the groups.

Therefore, early intervention and rehabilitation is essential for children with WS as well the profoundly hearing impaired. This will ensure that they are offered better conditions to achieve good outcomes with a cochlear implant. Parental involvement throughout the rehabilitation process is also important for improving the quality of communication.

Results from case 10 were not satisfactory despite having early intervention and childhood rehabilitation. On the other hand, the patient has not used the cochlear implant for very long, and these results may improve over time. 
Genetic counseling is important for predicting the risk of transmission as well as for studying the family of the affected individual $(21,22)$, and genetic findings may influence the prognosis and treatment opportunities.

\section{CONClusion}

In our group of patients with WS who received a cochlear implant, hearing thresholds that allow access to speech sounds were achieved. However, those who showed good evolution of the perception of auditory and oral language skills were those who received early stimulation, systematic rehabilitation, and who had a family that was actively involved in the process.

\section{REFERENCES}

1. Guedes MC, Weber R, Gomez MV, Neto RV, Peralta CG, Bento RF. Influence of evoked compound action potential on speech perception in cochlear. Braz J Otorhinolaryngol. 2007;73(4):439-45.

2. Moret A, Bevilacqua M, Costa O. [Cochlear implant: hearing and language in pre-lingual deaf children]. Pro Fono. 2007;19(3):295-304.

3. Kubo T, Iwaki T, Sasaki T. Auditory perception and speech production skills of children with cochlear. ORL J Otorhinolaryngol Relat Spec. 2008;70(4):224-8.

4. Nayak CS, Isaacson G. Worldwide distribution of Waardenburg syndrome. Ann Otol Rhinol Laryngol. 2003;112(9 Pt 1):817-20.

5. Smith DW. Síndrome de Waardenburg, Tipos I e II. In: Smith DW, editor. Síndromes de malformações congênitas. 3rd ed. São Paulo: Manole; 1989. p. 192-3.

6. Hageman MJ, Dalleman JW. Heterogeneity in Waardenburg's Syndrome. Am J Hum Genet. 1977;29:46885.

7. Sugii A, Iwaki T, Doi K, Takahashi Y, Yamamoto K, Fuse Y, et al. Cochlear implant in a young child with Waardenburg syndrome. Adv Otorhinolaryngol. 2000;57:215-9.

8. Migirov L, Henkin Y, Hildesheimer M, Muchnik C, Kronenberg J. Cochlear implantation in Waardenburg's syndrome. Acta Otolaryngol. 2005;125(7):713-7.

9. Cullen RD, Zdanski C, Roush P, Brown C, Teagle H, Pillsbury HC, 3rd, et al. Cochlear implants in Waardenburg syndrome. Laryngoscope. 2006;116(7):1273-5.
10. de Sousa Andrade SM, Monteiro AR, Martins JH, Alves MC, Santos Silva LF, Quadros JM, et al. Cochlear implant rehabilitation outcomes in Waardenburg syndrome children. Int J Pediatr Otorhinolaryngol. 2012;76(9):1375-8.

11. Bureau Internacional d'Audio Phonologie Bureau Internacionald'Audio Phonologie Audiometric classification of hearing impairment: recommendation 02/1 [Internet]1996. [cited 2010]. Available from: http:// www.biap.org/biapanglais/rec021eng.htm.

12. Goffi-Gomez M, Guedes M, Sant.Anna S, Peralta C, Tsuji R, Castilho A, et al. Critérios de Seleção e Avaliação Médica e Audiológica dos Candidatos ao Implante Coclear: Protocolo HCFMUSP. Arquivos Int Otorrinolaring. 2004;8(4):303-13.

13. Orlandi A, Bevilacqua M. Deficiência auditiva profunda nos primeiros anos de vida: procedimento para a avaliação da percepção de fala. Pró-Fono 1998;10(2):87-91.

14. Bevilacqua MC, Tech EA. Elaboração deum procedimento de avaliação de percepção de fala em crianças deficientes auditivas profundas a partir de cinco anos de idade. In: Marchesan I, Zorzi J, Gomes I, editors. Tópicos em Fonoaudiologia. São Paulo: Lovise; 1996. p. 411-33.

15. Geers AE. Techniques for assessing auditory speech perception and lipreading enhancement in young deaf children. The Volta Review. 1994;96(5):85-96.

16. Robbins AM, RenshawJJ, Berry SW. Evaluating meaningful auditory integration in profoundly hearing-impaired. Am J Otol. 1991;12 Suppl:144-50.

17. Castiquini EAT, Bevilacqua MC. Escala de integração auditiva significativa: procedimento adaptado para a avaliação da percepção da fala. Rev Soc Brasileira de Fonoaudiologia. 2000;6:51-60.

18. Robbins AM, Osberger MJ. Meaningful Use of Speech Scale (MUSS). Indianopolis: Indiana University School of Medicine. 1990.

19. Nascimento LT. Uma proposta de avaliação da linguagem oral. Bauru: Hospital de Pesquisa e Reabilitação de Lesões lábio-Palatais; 1997.

20. Protocolo Latino Americano para Implantes Cocleares, (2003).

21. Barzotto JDV, Folador MF. Síndrome de Waardenburg: características audiológicas. Rev CEFAC 2004;6(3):306-11.

22. Aquino TJM, Oliveira JAA, Anselmo-Lima W'T, Motonaga 
SM, Feres MCLC. Síndrome de Waardenburg e perda auditiva -implicações clínicas e aconselhamento genético. Rev Bras Otorrinol. 1997;63(4):353-59.

23. Russo ICP, Behlau M. As pistas acústicas das vogais e consoantes. In: Russo ICP, Behlau M, editors. Percepção da fala: análise acústica do português brasileiro. São Paulo: Lovise; 1993.

24. Daneshi A, Hassanzadeh S, Farhadi M. Cochlear implantation in children with Waardenburg syndrome. J Laryngol Otol. 2005;119(9):719-23.
25. Miyamoto RT, Hay-McCutcheon MJ, Kirk KI, Houston DM, Bergeson-Dana T. Language skills of profoundly deaf children who received cochlear implants under. Acta Otolaryngol. 2008;128(4):373-7.

26. Profant M, Kabatova Z, Simkova L. From hearing screening to cochlear implantation: cochlear implants in children. Acta Otolaryngol. 2008;128(4):369-72.

27. Stuchi R, Nascimento L, Belivacqua M, Brito Neto R. Linguagem oral de crianças com cincoanos deusodoimplante coclear. Pró-Fono R. Atual. Cient. 2007;19(2):167-76. 